\title{
VALOR JUSTIÇA: O FUNDAMENTO DO ORDENAMENTO JURÍDICO QUE IMPULSIONA O DIREITO PARA ALÉM DA MÁXIMA DURA LEX SED LEX
}

\author{
Fabiana Vergílio Souto, Augusta Rodrigues Westin Ebaid \\ Universidade do Oeste Paulista - UNOESTE, curso de Direito, Presidente Prudente, SP. E-mail: \\ fabianavergiliosouto@hotmail.com
}

\begin{abstract}
RESUMO
A justiça é o fundamento do ordenamento jurídico e a finalidade do Estado em proporcionar o bem comum, a harmonia social, só se concretiza em uma sociedade justa, que esteja satisfeita com os mecanismos de pacificação social utilizados pelo ente estatal. Exatamente por isso, a tarefa do intérprete e de todos aqueles que operam o Direito deve pautar-se na justiça, lançandoo para além do contexto meramente normativo, em uma época social em que a concepção dura lex sed lex ${ }^{1}$ não tem mais sentido prático. Para dar sequência e fundamentação teórica a presente pesquisa, utilizou-se como principal mecanismo de investigação, a busca de material bibliográfico, mais especificamente livros escritos, e do formato digital, e jurisprudência.
\end{abstract}

Palavras-chave: Direito, valores, justiça, moral, interpretação humanística.

\section{JUSTICE VALUE: THE BASIS OF LEGAL ORDINANCE THAT IMPULSATES THE RIGHT TO BEYOND AFORISM DURA LEX SED LEX}

\begin{abstract}
Justice is the foundation of the legal order and the State's purpose in providing the common good, social harmony, is only realized in a just society, which is satisfied with the mechanisms of social pacification used by the state entity. It is precisely for this reason that the task of the interpreter and of all those who operate the law must be based on justice, moving it beyond the merely normative context, in a social epoch in which the conception dura lex sed lex has no practical meaning anymore. In order to follow up and theoretical basis the present research, the search of bibliographical material, more specifically written books, and of the digital format, and jurisprudence, was used as main mechanism of investigation.
\end{abstract}

Keywords: Law, values, justice, moral, humanistic interpretation.

\section{INTRODUÇÃO}

A concepção de justiça é histórica, ideológica e impregnada de variados pontos de vista. A justiça e o Direito não podem ser tidos como conceitos, cujo objetivo se confunde. A proeminência da justiça está na sua importância prática, na possibilidade que carrega em seu bojo de se ter um conhecimento de como o Direito foi justaposto a um caso concreto, admitindo que se examine se tal subsunção foi apropriada ou não segundo o conceito de justiça.

Há um assíduo problema em se conceituar o Direito, diante da existência de múltiplas apreciações liberais, positivas, além de direitos naturais, percebemos o Direito em um sentido amplo, que compreende a Constituição como o preceito basilar, a lei, a jurisprudência e as atividades características do Poder Executivo, percebidas como atos da administração, como os regulamentos, portarias, decisões administrativas etc. (GARCIA, 2010).

\footnotetext{
${ }^{1}$ Expressão em latim, cujo significado é "a lei é dura, mas é lei". 
VALOR JUSTIÇA: O FUNDAMENTO DO ORDENAMENTO JURÍDICO QUE IMPULSIONA O DIREITO PARA ALÉM DA MÁXIMA DURA LEX SED LEX

O Estado, abstratamente, detém o poder-dever de legislar, advém, porém que este é constituído por indivíduos. Logo, a capacidade intelectual humana é o que articula a máquina legislativa e automaticamente a judiciária.

A legitimidade de uma norma não a torna justa ou moral. Esta é adjudicada pela legitimação concretizada pela autoridade competente do Estado, enquanto o valor emana do indivíduo em si. Realmente, deriva da análise da consciência do ser humano.

Decorre então que, os juízos de valor e de validade importam conceitos diferentes. Tal distinção funda a essência do diálogo entre o juspositivismo e o jusnaturalismo, igualmente, ensejando a conclusão de que nem toda norma é moral, mas sim, dotadas de validade contextual (GARCIA, 2010).

A classificação de justo e por consequência legitimo, apesar de intricada acepção, está relacionada assiduamente com o entendimento de Vasconcelos (1998, p. 23): “o Direito, inclusive para merecer o acatamento geral que o tornará eficaz, deve, pois, requalificar-se. Precisa ser também justo. Direito justo."

As exposições acima evidenciam a altercação histórica entre o direito natural e o direito positivo, uma vez que os jusnaturalistas recusam e afastam o atributo de Direito aos que sopesam como Direito injusto, considerando que para tal corrente de pensamento, o valor justo é o próprio Direito, como elementos compositores de um mesmo objeto, indistintamente.

Por sua vez, os juspositivistas, fundeados no clássico pensamento kelseniano, asseveram que a ideia acerca de justiça é distinta do conceito de Direito, podendo este ser classificado como justo ou injusto e continuar sendo Direito, logo a questão da justiça e injustiça, seriam valores passíveis de atribuição ao Direito, mas que este não pode ser entendido como sinônimo de tais atributos (NADER, 2011).

Na comparação entre a norma jurídica objetivamente válida e a abstrata apreciação de justiça, hiberna uma das mais atribuladas problemáticas acerca do tema, pois parte da doutrina assevera que, se o direito positivo não conjectura o ideal valorativo de justiça, a sociedade está sujeita a uma norma que, embora seja antes de tudo, jurídica, não é justa, é uma lacuna legal, visto que corresponderia a um não-direito, que embora previsto em lei, não se aplica adequadamente ao caso concreto (REALE, 2002).

Em consequência disso, a norma assim produzida apronta, por não ser jurídica e, por essa razão, não resguardada pelos regimes democráticos, o que leva à conclusão de que ela não deveria ser correspondida, contudo alentar o Direito Natural, que seria, em derradeira apreciação, o direito positivo em sua essência ideal.

Tal desempenho sugere a existência de ordem e justiça quando se averigua a segurança em uma determinada ordem social. Ambos os conceitos se aludem, porém não se confundem. Vasconcelos (2006, p. 18), diferencia: "sem ordem não há como fazer justiça e sem justiça não há meio de manter a ordem".

O que é realizado no exercício jurídico é a normatização dos princípios gerais do Direito, almejando adequar os valores que tais princípios trazem na sua essência às circunstâncias sobrevindas do convívio social, derivando o Direito de uma multiplicidade de elementos.

Ensina Nunes (2015, p. 362): “a justiça pode ser descrita como uma qualidade subjetiva do indivíduo, uma virtude, mas virtude especial traduzida na fórmula: vontade constante de dar a cada um aquilo que é seu".

A justiça deve ser, subsidiariamente, subjetiva e objetiva, envolvendo em sua dialeticidade o homem e a ordem justa que ele instaura, uma vez que tal ordem não é senão uma projeção da 
pessoa humana, considerado como valor-fonte de todos os valores através do tempo (NUNES, 2015, p. 363).

Não devem ser abstraídas do Direito as influências de motes morais, religiosas, políticas e econômicas no ordenamento, que muitas vezes são decisivas na esfera legislativa e possibilitam flexibilidade ao multiverso jurídico. Nos estudos de Machado Paupério:

O direito positivo, ainda que não se constitua de meras essências de valor, é uma obra humana de interpretação e de realização valorativa, dentro das circunstâncias históricas que encontra. Em sua relação recíproca com a justiça, nem sempre direito positivo alcança o grau desejável, para tornarse o direito justo a que todos nós aspiramos. Contudo, não existe norma de direito positivo sem valoração. A norma positiva é sempre expressão de um juízo de valor. Sem este, não existiria o próprio direito positivo. (PAUPÉRIO, 1977, p.163).

Restringir a ideia acerca de justiça aos conceitos de igualdade ou equidade, em virtude de limitados princípios através dos quais é possível realizar comparações, pode acarretar conflitos e dicotomicamente irromper injustiças, pois o Direito não pode ser reduzido à fórmulas aplicáveis a depender do caso concreto. Há um conteúdo, para além daquele meramente normativo que adequa o Direito à sociedade que o constituiu paulatinamente. E a mesma sociedade que estabelece leis por meio de seus representantes guiados pelas forças sociais, também clama por uma aplicação justa desse mecanismo de ordem social, que nem sempre é aplicado a contento.

Como a semente que, cheia de vida, aguarda indormida, debaixo da terra, a ação da chuva para expandir sua fecundidade, o Direito Subjetivo, atuante no processo, seja como réu, seja como autor, vai ao encontro da sentença, a partir da qual e por ação da qual passa a expandir sobre a sociedade sua vitalidade (COSTA, 1996, p. 94-95).

Para ilustrar a incidência valorativa na interpretação e subsunção da norma, a decisão judicial de primeiro grau proferida pelo juiz Gerivaldo Alves Neiva ${ }^{2}$ é um exemplo de exercício humanístico:
B.S.S. é surdo e mudo, tem 21 anos e é conhecido em Coité como "Mudinho".
Quando criança entrava nas casas alheias para merendar, jogar videogame, para trocar de roupa, para trocar de tênis e, depois de algum tempo, também para levar algum dinheiro ou objeto.
Conseguia abrir facilmente qualquer porta, janela, grade, fechadura ou cadeado.
Domou os cães mais ferozes, tornando-se amigo deles.
Abria também a porta de carros e dormia candidamente em seus bancos.
Era motivo de admiração, espanto e medo!
O Ministério Público ofereceu dezenas de Representações contra o então adolescente B.S.S. pela prática de "atos infracionais" dos mais diversos. O Promotor de Justiça, Dr. José Vicente, quase o adotou e até o levou para brincar com seus filhos, dando-lhe carinho e afeto, mas não teve condições de cuidar do "Mudinho".

\footnotetext{
${ }^{2}$ Juiz de Direito da Comarca de Conceição de Coité - Bahia.
} 
O Judiciário o encaminhou para todos os órgãos e instituições possíveis, ameaçou prender Diretoras de Escolas que não o aceitava, mas também não teve condições de cuidar do "Mudinho".

A comunidade não fez nada por ele.

O Município não fez nada por ele.

O Estado Brasileiro não fez nada por ele.

Hoje, B.S.S. tem 21 anos, é maior de idade, e pratica crimes contra o patrimônio dos membros de uma comunidade que não cuidou dele.

Foi condenado, na vizinha Comarca de Valente, como "incurso nas sanções do art. 155, caput, por duas vezes, art. 155, § 4으, inciso IV, por duas vezes e no art. 155, $\S 40$, inciso IV c/c art. 14, inciso II", a pena de dois anos e quatro meses de reclusão.

Por falta de estabelecimento adequado, cumpria pena em regime aberto nesta cidade de Coité.

Aqui, sem escolaridade, sem profissão, sem apoio da comunidade, sem família presente, sozinho, às três e meia da manhã, entrou em uma marmoraria e foi preso em flagrante. Por que uma marmoraria?

Foi, então, denunciado pelo Ministério Público pela prática do crime previsto no artigo 155, §4으, incisos II e IV, c/c o artigo 14, II, do Código Penal, ou seja, crime de furto qualificado, cuja pena é de dois a oito anos de reclusão.

Foi um crime tentado. Não levou nada.

Por intermédio de sua mãe, foi interrogado e disse que "toma remédio controlado e bebeu cachaça oferecida por amigos; que ficou completamente desnorteado e então pulou o muro e entrou no estabelecimento da vítima quando foi surpreendido e preso pela polícia". Em alegações finais, a ilustre Promotora de Justiça requereu sua condenação "pela pratica do crime de furto qualificado pela escalada".

B.S.S. tem péssimos antecedentes e não é mais primário. Sua ficha, contando os casos da adolescência, tem mais de metro.

O que deve fazer um magistrado neste caso? Aplicar a Lei simplesmente? Condenar B.S.S. à pena máxima em regime fechado?

O futuro de B.S.S. estava escrito. Se não fosse morto por um "proprietário" ou pela polícia, seria bandido. Todos sabiam e comentavam isso na cidade. Hoje, o Ministério Público quer sua prisão e a cidade espera por isso. Ninguém quer o "Mudinho" solto por aí. Deve ser preso. Precisa ser retirado do seio da sociedade. Levado para a lixeira humana que é a penitenciária. Lá é seu lugar. Infelizmente, a Lei é dura, mas é a Lei!

O Juiz, de sua vez, deve ser a "boca da Lei".

Será? O Juiz não faz parte de sua comunidade? Não pensa? Não é um ser humano? De outro lado, será que o Direito é somente a Lei? E a Justiça, o que será? Poderíamos, como já fizeram tantos outros, escrever mais de um livro sobre esses temas.

Nesse momento, no entanto, temos que resolver o caso concreto de B.S.S. O que fazer com ele? Nenhuma sã consciência pode afirmar que a solução para B.S.S. seja a penitenciária. Sendo como ela é, a penitenciária vai oferecer a B.S.S. tudo o que the foi negado na vida: escola, acompanhamento especial, afeto e compreensão? Não. Com certeza, não! 
É o Juiz entre a cruz e a espada. De um lado, a consciência, a fé cristã, a compreensão do mundo, a utopia da Justiça... Do outro lado, a Lei. Neste caso, prefiro a Justiça à Lei.

Assim, B.S.S., apesar da Lei, não vou lhe mandar para a penitenciária.

Também não vou lhe absolver.

Vou lhe mandar prestar um serviço à comunidade.

Vou mandar que você, pessoalmente, em companhia de Oficial de Justiça desse Juízo e de sua mãe, entregue uma cópia dessa decisão, colhendo o "recebido", a todos os órgãos públicos dessa cidade - Prefeitura, Câmara e Secretarias Municipais; a todas as associações civis dessa cidade - ONGs, clubes, sindicatos, CDL e maçonaria; a todas as Igrejas dessa cidade, de todas as confissões; ao Delegado de Polícia, ao Comandante da Polícia Militar e ao Presidente do Conselho de Segurança; a todos os órgãos de imprensa dessa cidade e a quem mais você quiser.

Aproveite e peça a eles um emprego, uma vaga na escola para adultos e um acompanhamento especial. Depois, apresente ao Juiz a comprovação do cumprimento de sua pena e não roubes mais!

Expeça-se o Alvará de Soltura.

A partir dessa decisão é possível deslindar que não há sentido em isolar o Direito das suas raízes axiológicas, se o próprio julgador utiliza componentes valorativos para fundamentar as decisões proferidas, já que como todos, está inserido em um meio social construído a partir de cultura histórica, ideologias, princípios e bases valorativas em geral (NADER, 2011).

A tentativa de expurgar da norma qualquer forma de valoração cerceia a interpretação, expressão e intervenção do homem, respeitáveis componentes do método científico. ${ }^{3}$

\section{CONCLUSÃO}

No caso supracitado, o intérprete orientou sua conduta e ação por aquilo que mais parecia ser justo ou, pelo menos, o que demonstrou ser mais razoável, de "bom senso", segundo seu alicerce cultural axiológico. Consoante a isso se colige que não há possibilidade de haver justiça, sem que haja pessoas justas atuando em favor de tal valor.

Dura lex sed lex é uma concepção ultrapassada, reacionária e incoerente diante dos clamores sociais. A interpretação do Direito, vinculando as normas aos valores, principalmente ao valor justiça, fundamento do ordenamento jurídico, frente às verdadeiras aspirações sociais, aproximando os mecanismos normativos do principal objetivo jurídico, a pacificação social. Logo, o valor justiça atua como elemento propulsor, impulsionando o Direito para um patamar superior, para além do campo legalista, atendendo à finalidade última do Estado, qual seja, o bem comum.

\section{REFERÊNCIAS BIBLIOGRÁFICAS}

COSTA, Elcias Ferreira. A essência trinitária do direito. Porto Alegre: Fabris, 1996.

FERRAZ JÚNIOR, Tércio Sampaio. A função social da dogmática jurídica. São Paulo: Atlas. 2015.

GARCIA, Gustavo Filipe Barbosa. Introdução ao estudo do direito. São Paulo: Método, 2010.

\footnotetext{
${ }^{3}$ Encarando-se a decisão judicial como um processo extremamente axiológico, possibilita-se maior acessibilidade ao Poder Judiciário.
} 
NADER, Paulo. Introdução ao estudo do direito. Rio de Janeiro: Forense, 2011.

NEIVA, Gerivaldo Alves. A crônica de um crime anunciado. Boletim CEDES (on-line), Rio de Janeiro, julho e agosto de 2008, p. 10-12. Disponível em: http://www.cedes.iuperj.br. Acessado em: 07 abril 2017.

NUNES, Rizzatto. Manual de filosofia do direito. 6. ed. São Paulo: Saraiva, 2015.

PAUPÉRIO, Arthur Machado. Introdução axiológica do direito. Rio de Janeiro: Forense, 1977.

REALE, Miguel. Filosofia do Direito. 20. ed. São Paulo: Saraiva, 2002.

. Lições Preliminares do Direito. 26. ed. São Paulo: Saraiva, 2002.

VASCONCELOS, Arnaldo. Direito, Humanismo e Democracia. 3. ed. São Paulo: Malheiros, 1998.

Teoria Pura do Direito: repasse crítico de seus principais fundamentos. Rio de Janeiro: Forense, 2003. 